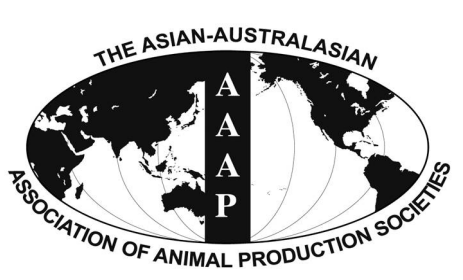

Open Access

Asian Australas. J. Anim. Sci.

Vol. 29, No. 7 : 1037-1043 July 2016

http://dx.doi.org/10.5713/ajas.15.0459

www.ajas.info

pISSN 1011-2367 elSSN 1976-5517

\title{
Characterization of the Methylation Status of Pax7 and Myogenic Regulator Factors in Cell Myogenic Differentiation
}

\author{
Zhe Chao, Xin-Li Zheng, Rui-Ping Sun, Hai-Long Liu, Li-Li Huang, Zong-Xi Cao, \\ Chang-Yan Deng', and Feng Wang* \\ Institute of Animal Sciences and Veterinary, Hainan Academy of Agricultural Sciences, Haikou 571100, China
}

\begin{abstract}
Epigenetic processes in the development of skeletal muscle have been appreciated for over a decade. DNA methylation is a major epigenetic modification important for regulating gene expression and suppressing spurious transcription. Up to now, the importance of epigenetic marks in the regulation of $\operatorname{Pax} 7$ and myogenic regulatory factors (MRFs) expression is far less explored. In the present study, semi-quantitative the real-time polymerase chain reaction (RT-PCR) analyses showed $M y o D$ and $M y f 5$ were expressed in activated and quiescent $\mathrm{C} 2 \mathrm{C} 12$ cells. $M y o G$ was expressed in a later stage of myogenesis. Pax 7 was weakly expressed in differentiated $\mathrm{C} 2 \mathrm{C} 12$ cells. To further understand the regulation of expression of these genes, the DNA methylation status of $\operatorname{Pax} 7, M y o D$, and $M y f 5$ was determined by bisulfite sequencing PCR. During the $\mathrm{C} 2 \mathrm{C} 12$ myoblasts fusion process, the changes of promoter and exon 1 methylation of $\operatorname{Pax} 7, M y o D$, and $M y f 5$ genes were observed. In addition, an inverse relationship of low methylation and high expression was found. These results suggest that DNA methylation may be an important mechanism regulating Pax7 and MRFs transcription in cell myogenic differentiation. (Key Words: Pax7, Myogenic Regulatory Factors, C2C12, DNA Methylation, CpG Islands)
\end{abstract}

\section{INTRODUCTION}

The Pax gene family defines an evolutionary conserved group of transcription factors that play critical roles during organogenesis and tissue homeostasis (Olguin et al., 2007). Two members of the Pax family of transcriptional factors, Pax3 and Pax7, are supposed to be involved in the myogenic cell specification (Horst et al., 2006). The Pax7 gene is indeed a key regulator of muscle cell differentiation in specific populations of adult stem cells and is a good candidate to distinguish activated satellite cells (Caliaro et al., 2005).

Differentiation of mammalian skeletal muscle cells is regulated by members of the $M y o D$ family of myogenic regulatory factors (MRFs). These include $M y o D, M y f 5$, myogenin, and MRF4 (Weintraub, 1993). Cultured

\footnotetext{
* Corresponding Author: Feng Wang. Tel: +86-898-65314685, Fax:+86-898-65314685, E-mail: 503911940@qq.com

${ }^{1}$ College of Animal Science, Huazhong Agricultural University, Wuhan 430070, China.

Submitted May 25, 2015; Revised Oct. 1, 2015; Accepted Nov. 13, 2015
}

myoblasts express one or others of these markers as well. $M y o D$ and $M y f 5$ are required for commitment to myogenic lineage. Myogenin and MRF4 have been reported to have a role in terminal differentiation of the myoblasts (Abe et al., 2009). MRFs and Pax 7 appear to play critical roles during satellite cell activation, proliferation and differentiation. Pax7 is expressed almost ubiquitously by quiescent satellite cells and is co-expressed with $M y o D$ in their proliferating myoblast progeny (Collins et al., 2009). In C2C12 immortalised myoblasts, $\operatorname{Pax} 7$ has recently been shown to induce chromatin modifications through association with a histone methyltransferase complex and direct binding to regulatory regions of the Myf5 locus. Although some results provide evidence for a functional relationship between Pax7 and the MyoD family of transcription factors, the exact nature of this relationship is controversial.

DNA methylation at $\mathrm{CpG}$ dinucleotides is a well-studied epigenetic mechanism, defined as a heritable and enzymeinduced chemical modification of DNA, not altering the DNA sequence (Wu et al., 2007). The frequency of $\mathrm{CpG}$ dinucleotides is strikingly low in the mammalian genome. 
However, approximately half of the human gene promoter regions contain dinucleotide clusters of CpGs, known as "CpG islands". A large number of experiments have shown that methylation of promoter $\mathrm{CpG}$ islands plays an important role in the regulation of gene expression, genomic imprinting, mammalian development, inactivation of the $\mathrm{X}$ chromosome, and carcinogenesis (Takai and Jones, 2002; Palacios and Puri, 2006; Nakamura et al., 2014).

Epigenetic changes occur within muscle cells during development, maturation and regeneration. During development, the determination of mesenchymal cells to either a myogenic, adipogenic, osteogenic or chrondrogenic lineage is in part due to stable modifications made to the methylation pattern of DNA that prevents the transcription of genes from other lineages (Barr, 2010). The DNA methylation states of Pax7 and MRFs may serve as an effective indicator of the degree of cell myogenic differentiation. To this purpose, we examined the methylation profile expression of $\operatorname{Pax} 7$ and $M R F s$ in the mouse skeletal muscle precursor cell line $\mathrm{C} 2 \mathrm{C} 12$. Realtime polymerase chain reaction (RT-PCR) and bisulfite genomic sequencing show a correlation between the state of DNA methylation within the promoter or exon1 CpGislands and the levels of $\operatorname{Pax} 7$ and $M R F$ s expression in cell myogenic differentiation. These findings suggest that DNA methylation is a major regulator of $\operatorname{Pax} 7$ and $M R F S$ transcription in cell myogenic differentiation.

\section{MATERIALS AND METHODS}

\section{Cell culture}

The $\mathrm{C} 2 \mathrm{C} 12$ (mouse) skeletal muscle cell line was obtained from the American Type Culture Collection (Nos. CRL-1772). The cell line was cultured in Dulbecco's modified eagle medium (DMEM) (Invitrogen, Carlsbad, CA, USA) supplemented with $10 \%$ (vol/vol) fetal bovine serum (Invitrogen, USA), $100 \mathrm{U} / \mathrm{mL}$ penicillin, and 100 $\mu \mathrm{g} / \mathrm{mL}$ streptomycin (Invitrogen, USA) as recommended by the supplier. $\mathrm{C} 2 \mathrm{C} 12$ cells were cultured in DMEM containing $2 \%$ horse serum (Invitrogen, USA) for differentiation, and harvested at various times $(0,1,3,5,8$, or 10 days).

\section{RNA extraction, cDNA synthesis, and semi-quantitative RT-PCR}

Total RNA was isolated from the cells with TRIzol Reagent (Invitrogen, USA) according to standard protocols, and the reverse transcription was performed based on the method described previously by Qiao et al. (2010). The PCR primer sequences used for semi-quantitative RT-PCR for Pax7 (NM_011039.2), MyoD (NM_010866.2), Myf5 (NM_008656.5), myogenin (NM_031189.2), and glyceraldehyde-3-phosphate dehydrogenase (GAPDH) (NM_008084.2) are presented in Supplemental Table 1. The sequences of these genes were obtained from GenBank database.

The Pax7 and MRFs genes mRNA expression in cell myogenic differentiation were detected by semi-quantitative RT-PCR with the GAPDH gene as an internal control, and all PCRs were performed in triplicate. PCR amplifications were carried out in a $50 \mu \mathrm{L}$ reaction mixture containing 2 $\mu \mathrm{L}$ normalized template cDNA, $1.0 \mu \mathrm{L}$ of each primer $(5$ $\mu \mathrm{M}), 4.0 \mu \mathrm{L}$ of each dNTP $(2 \mathrm{mM}), 5.0 \mu \mathrm{L}$ of $10 \times \mathrm{PCR}$ buffer, $4.0 \mu \mathrm{L}$ of $(25 \mathrm{mmol} / \mathrm{L}) \mathrm{Mg}^{2+}$ and $2 \mu \mathrm{L}(1 \mathrm{U} / \mu \mathrm{L})$ of Taq DNA polymerase (Fermentas, Burlington, ON, Canada) and $31.0 \mu \mathrm{L}$ sterile water. The PCR amplification profiles were as follows: $94^{\circ} \mathrm{C}$ initial denaturation for $4 \mathrm{~min}, 35$ cycles of $94^{\circ} \mathrm{C}$ denaturation for $40 \mathrm{~s}, 59^{\circ} \mathrm{C}$ to $65^{\circ} \mathrm{C}$ annealing for $40 \mathrm{~s}$, and $72^{\circ} \mathrm{C}$ extension for 15 to $20 \mathrm{~s}$ (according the length of the target fragments), followed by a 10 min extension at $72^{\circ} \mathrm{C}$.

\section{DNA isolation and bisulfite modification}

Genomic DNA was extracted from the cells according

Table 1. Primers used for nested polymerase chain reaction

\begin{tabular}{|c|c|c|c|c|}
\hline Gene & Primer name & Primer sequence $\left(5^{\prime} \rightarrow 3^{\prime}\right)$ & $\mathrm{AT}\left({ }^{\circ} \mathrm{C}\right)$ & Size (bp) \\
\hline \multirow[t]{4}{*}{ MyoD } & Outside forward & ATTTAGGAATTGGGATATGGAG & 62 & 402 \\
\hline & Outside reverse & AАAАCСТCATTCACTTTACTCAAA & & \\
\hline & Inside forward & TAGGAATTGGGATATGGAGTTTT & 63 & 309 \\
\hline & Inside reverse & TTACAAACCCACAACAAACAAC & & \\
\hline \multirow[t]{4}{*}{ Myf5 } & Outside forward & GGTATTTTTGAAAGGTTTTTGTT & 58 & 417 \\
\hline & Outside reverse & AAATAAACCAAATAACCTTCCC & & \\
\hline & Inside forward & GGTGTTAGTTGGTTTGAAAAGT & 60 & 300 \\
\hline & Inside reverse & AAATAAACCAAATAACCTTCCC & & \\
\hline \multirow[t]{4}{*}{$\operatorname{Pax} 7$} & Outside forward & TAGGGTGTGAGGGTTAGTAGAA & 60 & 297 \\
\hline & Outside reverse & ACAAAAAAATTCAAACAAACAAA & & \\
\hline & Inside forward & GGTGTGAGGGTTAGTAGAAAGA & 61 & 291 \\
\hline & Inside reverse & AAAAAATTCAAACAAACAAACACT & & \\
\hline
\end{tabular}


to the standard phenol-chloroform method and stored at $-20^{\circ} \mathrm{C}$. About 0.5 to $1 \mu \mathrm{g}$ of genomic DNA was used for subsequent modification. Bisulfite treatment converting all cytosine residues except 5-methylcytosine to uracil was performed by established protocols (Frommer et al., 1992).

\section{PCR amplification of bisulfite-modified DNA and sequencing}

All mutagenized DNA was subjected to three independent nested amplifications, to eliminate the sampling bias of PCR. About $2 \mu \mathrm{L}$ of bisulfite-treated DNA was amplified using specific primers (Table 1), which were designed by Methyl Primer Express Software v1.0 (ABI, Foster, CA, USA). Taq DNA polymerase (Fermentas, Canada) was used for the two rounds of PCR, following the annealing temperatures described in Table 1.

For sequence analysis, the PCR products were cloned into the pMD 18-T cloning vector (TaKaRa, Dalian, China) and 10 individual clones were sequenced.

\section{CpG islands identification}

$\mathrm{CpG}$ islands were predicted using an online software (http://www. urogene. org/meth primer/index1.html).

\section{RESULTS}

Expression analysis of $\operatorname{Pax} 7$ and MRFs genes in myogenic differentiation in $\mathrm{C} 2 \mathrm{C} 12$ cells

To investigate the differential expression of $\operatorname{Pax} 7$ and $M R F s$ during myoblasts differentiation, cultured $\mathrm{C} 2 \mathrm{C} 12$ myoblasts were induced to differentiate. Myotubes started to appear at day 3 and became more evident at days 5, 7, and 10 (Supplementary Figure S1). As shown in Figure 1, $M y o D$ and $M y f 5$ were expressed at $0 \mathrm{~d}$ with a relatively low level then increased to a peak at $3 \mathrm{~d}$. Myogenin was hardly expressed at $0 \mathrm{~d}$ and $1 \mathrm{~d}$, and then increased within the first

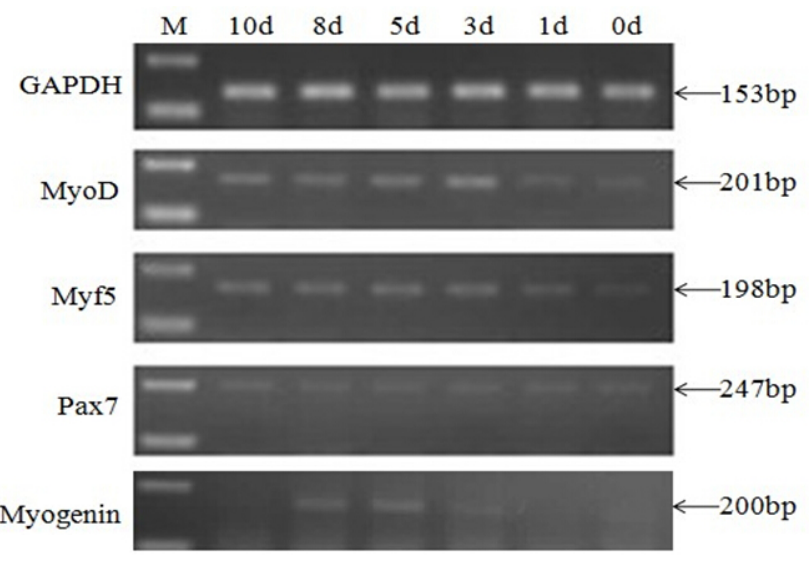

Figure 1. Expression analyses of $M R F s$ and $\operatorname{Pax} 7$ genes in differentiated $\mathrm{C} 2 \mathrm{C} 12$ cells. M: DNA Ladder. MRFs, myogenic regulatory factors.

$5 \mathrm{~d}$ after the induction of differentiation. Increased MyoD/Myf5/myogenin mRNA levels from $0 \mathrm{~d}$ to $5 \mathrm{~d}$ confirmed that the cells had undergone differentiation. During the whole duration of cell differentiation, a low level mRNA of Pax7 can be detected.

\section{DNA methylation pattern of the MyoD in myogenic differentiation}

To determine DNA methylation changes during myogenic differentiation of $\mathrm{C} 2 \mathrm{C} 12$ cells, we analyzed the methylation states around the promoter regions of several marker genes (MyoD, Myf5, and Pax7). Total genomic DNA was isolated from $\mathrm{C} 2 \mathrm{C} 12$ cells of $0 \mathrm{~d}, 3 \mathrm{~d}$, and $5 \mathrm{~d}$ (differentiation), respectively. DNA was treated with sodium bisulfite, chemically introduced a $\mathrm{C}$ to $\mathrm{T}$ conversion at unmethylated cytosines.

Firstly, the methylation status of the $M y o D$ gene was investigated. The mouse $M y o D$ gene sequence was determined including three exons and two introns. Figure

A

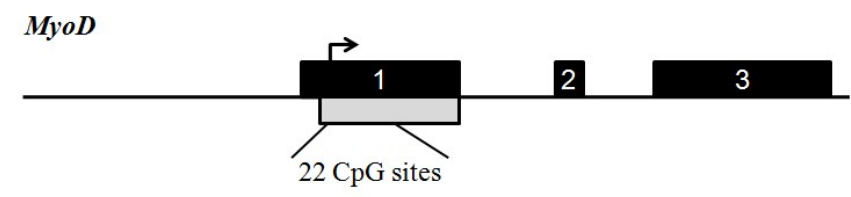

B

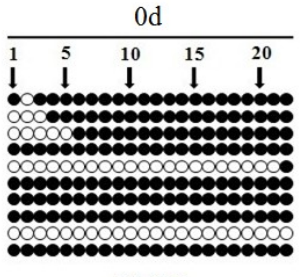

$76.4 \%$

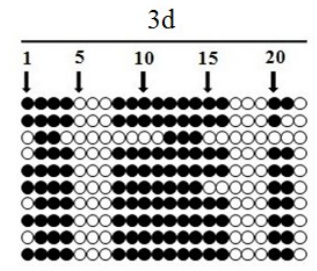

$60.9 \%$

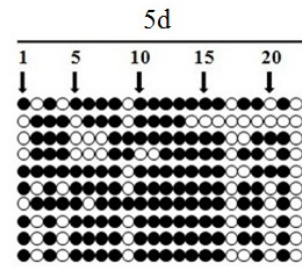

$69.1 \%$

Figure 2. Genomic structure of mouse $M y o D$ gene and relative $\mathrm{CpG}$ islands (A). Exons are depicted as solid boxes. Right-angled arrowhead indicates the translation start site. Open grey box represents $\mathrm{CpG}$ islands; the results of bisulfite sequencing analysis (B). Each line represents an individual sequence molecule, with each circle corresponding to a separate CpGs. Black and white circles indicate methylated and unmethylated $\mathrm{CpGs}$ respectively. 
$\mathbf{A}$

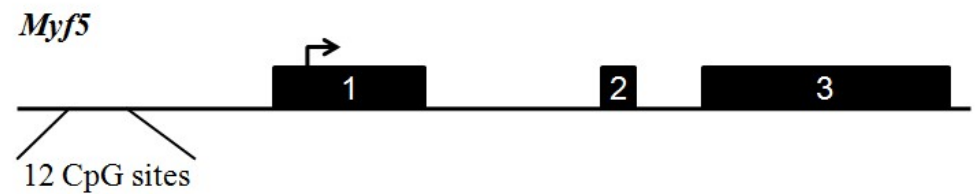

B

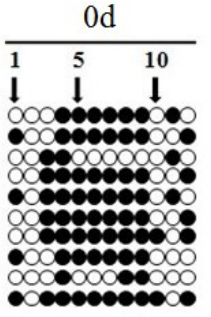

$60 \%$

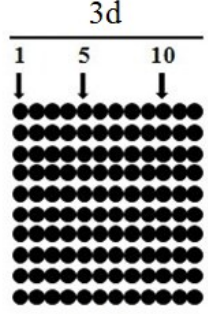

$100 \%$

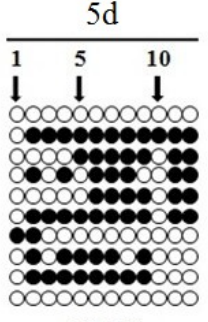

$47.5 \%$

Figure 3. Genomic structure of mouse Myf5 gene (A). Exons are depicted as solid boxes. Right-angled arrowhead indicates the translation start site; the results of bisulfite sequencing analysis (B). Each line represents an individual sequence molecule, with each circle corresponding to a separate CpGs. Black and white circles indicate methylated and unmethylated CpGs respectively.

2A illustrates the exon 1 region of the $M y o D$ gene where we might obtain a big CpG island in DNA sequence of $M y o D$ gene exon 1 from -50 to +618 bp (translation start site: +1 ). Bisulfite sequencing analysis indicated that a differentially methylated region was found from -13 to $+296 \mathrm{bp}$, which contains a total of $22 \mathrm{CpG}$ sites (Figure 2A). Methylation levels reached $76.4 \%, 60.9 \%$, and $69.1 \%$ at $0 \mathrm{~d}, 3 \mathrm{~d}$, and $5 \mathrm{~d}$, respectively (Figure $2 \mathrm{~B}$ ).

DNA methylation pattern of the $M y f 5$ in myogenic differentiation

Next, the research focused on the methylation status of the Myf5 gene, which contains three exons and two introns. Myf5 is devoid of $\mathrm{CpG}$ islands near the promoter and exon 1. The region $(-1,105$ to $-806 \mathrm{bp})$ with relatively high $\mathrm{CpG}$ density (12 CpG sites) was selected for methylation analysis (Figure 3A). A significant variation in methylation status of this region in $\mathrm{C} 2 \mathrm{C} 12$ cells of different stages of myogenic differentiation was observed. The percentage methylation of this region at $0 \mathrm{~d}, 3 \mathrm{~d}$, and $5 \mathrm{~d}$ was $60 \%$, $100 \%$, and $47.5 \%$, respectively (Figure $3 \mathrm{~B}$ ).

\section{DNA methylation pattern of the $\operatorname{Pax} 7$ in myogenic differentiation}

Analysis of the sequencing data revealed that the mouse Pax7 gene contains nine exons and eight introns. The structure of the analysed $\mathrm{CpG}$ islands and their locations within the Pax7 gene is shown in Figure 4A. We examined both of the first $\mathrm{CpG}$ islands, extending from -777 to -210 positions, and the second $\mathrm{CpG}$ island, extending from -106 to +529 positions, in the promoter and exon 1 of the $\operatorname{Pax} 7$ gene. A differentially methylated region was found in DNA

A

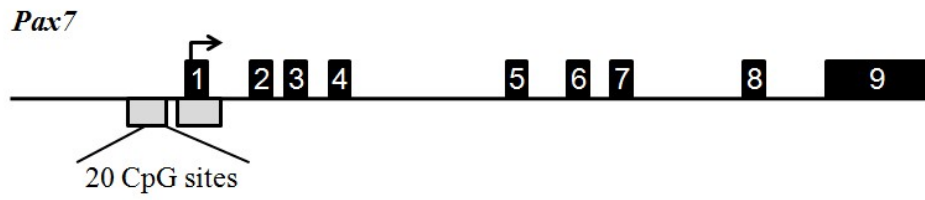

B

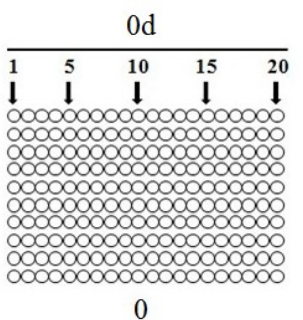

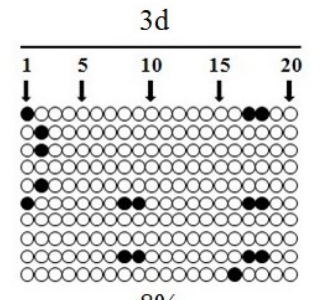

$8 \%$

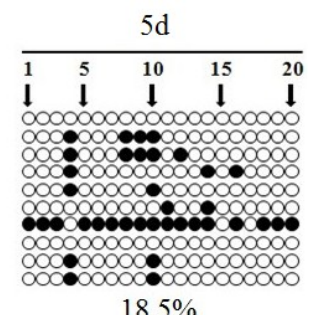

$18.5 \%$

Figure 4. Genomic structure of mouse Pax7 gene and relative $\mathrm{CpG}$ islands (A). Exons are depicted as solid boxes. Right-angled arrowhead indicates the translation start site. Open grey boxes represent $\mathrm{CpG}$ islands; the results of bisulfite sequencing analysis (B). Each line represents an individual sequence molecule, with each circle corresponding to a separate CpGs. Black and white circles indicate methylated and unmethylated CpGs respectively. 
sequence of Pax7 gene promoter from -517 to $-227 \mathrm{bp}$, which contains a total of $20 \mathrm{CpG}$ sites (Figure 4A). Methylation levels reached $0 \%, 8 \%$, and $18.5 \%$ at $0 \mathrm{~d}, 3 \mathrm{~d}$, and $5 \mathrm{~d}$, respectively (Figure 4B).

\section{DISCUSSION}

Skeletal muscle development occurs in several defined steps. Mesoderm-derived precursor cells become committed to the myogenic lineage and develop into myoblasts, which subsequently fuse to form myotubes. Later, myotubes mature into multinucleated, highly specialized muscle fibers that show cross striation (Steffens et al., 2011). Differentiation involves various cellular changes, including physiology, structural architecture and functions (Xiong et al., 2011). Every event in the course of differentiation should be accompanied by coordinated expression and/or repression of certain subsets of genes (Yeo et al., 2007). DNA methylation can regulate the expression of many vital genes while the base compositions of these genes do not change. It is very important to the growth and development of organism. Consequently, clarifying the relationship between gene expression and DNA methylation during C2C12 myoblasts fusion process should enhance our understanding of the molecular mechanism underlying muscle development.

Great care was taken in all the optimization steps for validating the semi-quantitative PCR method used in this study, and the appropriate controls were included. GAPDH was used as an internal housekeeping gene to normalize total RNA input and reaction efficiency. GAPDH has been used as an internal control because it is ubiquitously expressed, in moderately abundant levels in almost all cell types and in general, its expression is not influenced by any hormonal treatment (Ghai et al., 2010). In present system, the expression pattern of control gene in all samples studied was found to be uniform.

Previous work concerning $M y o D$ has indicated a constitutive expression at the myoblast stage (Dedieu et al., 2002). Some observations showed that the MRFs investigated are all expressed during postnatal phases of pig development although a descending trend was detected from day 1 towards day 20 and day 50 after birth for MyoD, Myf5, and myogenin but not myostatin and Pax7 (Caliaro et al., 2005). Our results complete these studies and show that $M y o D$ is expressed throughout the process of fusion and even at the later stages of differentiation. The methylation patterns we observed may be relevant to transcriptional silencing of the $M y o D$ gene, higher methylation being correlated with lower expression. Studies have shown that $\mathrm{CpG}$ islands are mainly distributed in the promoter and first exon of the genes (Butcher and Beck, 2008). In skeletal muscle tissues, the exon 1 hypermethylation status of myostatin gene was found to be negatively correlated with the gene expression (Liu et al., 2010). In addition, Kim et al. (2008) demonstrated prominent hypermethylation of $\mathrm{CpG}$ dinucleotides in TCF4 exon 1, which significantly correlates with gene inactivation in early stage gastric cancers and in intestinal-type gastric cancers.

The expression patterns of MyoD/Myf5/myogenin have proven that the cells undergo differentiation. Our data showed that $\mathrm{CpG}$ methylation in $\operatorname{Pax} 7$ promoter gradually increased in an day-dependent manner during differentiation of $\mathrm{C} 2 \mathrm{C} 12$ - the average percent of methylated $\mathrm{CpG}$ sites ranging from $0 \%$ at $0 \mathrm{~d}$ to $18.5 \%$ at 5 d. Fan et al. (2002) reported that $\mathrm{CpG}$ island methylation was a gradual process, that was, a cytosine base existing in each $\mathrm{CpG}$ island was gradually being methylated. The methylation of critical $\mathrm{CpG}$ sites decreases gene expression and causes gene silence. Over the past decade, a large number of studies focused on the mechanism of mRNA expression levels and methylation. Methyl groups of $\mathrm{CpG}$ sites can directly interfere with binding of transcription factors to their recognition cis elements or, on the other side, can facilitate interaction with a family of methyl-binding proteins. Upon binding to methylated DNA, these proteins can mask binding sites for transcription factors or recruit chromatin-modifying enzymes to silence particular DNA loci (Zelko et al., 2010).

There is not one standard $\mathrm{CpG}$ island in Myf5 gene sequence. So we chose to examine one region with relatively high $\mathrm{CpG}$ density. In the present study, methylation of the Myf5 gene is a dynamic process. Nevertheless, expression level of $M y f 5$ is not inversely correlated with DNA methylation status. It was reported that a third of the genes analyzed show inverse correlation between the state of DNA methylation in the 5'-regulatory regions and gene expression, whereas the methylation state did not correlate with mRNA expression levels for $63 \%$ of the genes (Eckhardt et al., 2006; Fan et al., 2011). These data suggest that chromosomal regions near the promoters of Myf5 gene do not contain the necessary cis-acting regulatory factors required for its expression, and that further studies are necessary to determine the mechanism of Myf5 expression. In addition, only one region with relatively high $\mathrm{CpG}$ density in promoter region of $M y f 5$ gene was investigated. The importance of the other regions needs further analysis and comparison.

The observed expression pattern of myogenin is in agreement with the published data. Myogenin is the only $M R F s$ gene expressed in all skeletal muscle cell lines. With the onset of myogenin expression, cells are withdrawn from the cell cycle and start to fuse into myofibres (Verner et al., 2007). Although there is a weak $\mathrm{CpG}$ island in myogenin promoter, it has been shown that methylation status of the weak $\mathrm{CpG}$ island plays an important role in the activation 
of myogenin (Steffens et al., 2011).

Collectively, our results indicate that DNA methylation within $\mathrm{CpG}$ islands during cell differentiation is associated with a variety of gene regulatory processes, including transcriptional regulation. However, one representative gene, Myf5, which does not contain canonical CpG islands within the promoter region, displays some degree of methylation upon differentiation. The gene expression seems to also be regulated by several mechanisms in addition to direct DNA methylation, suggesting that novel approaches are required to gain a comprehensive understanding of transcriptional regulation in myogenic differentiation.

\section{CONFLICT OF INTEREST}

We certify that there is no conflict of interest with any financial organization regarding the material discussed in the manuscript.

\section{ACKNOWLEDGMENTS}

This work was supported by the National Natural Science Foundation of China (31560628), National "863" project of China (2011AA100302), Hainan science projects (13-214002-0001, KYYS-2014-33, KYYS-2015-02) and Hainan Agricultural Science and Technology Innovation Project (CXZX201414).

\section{REFERENCES}

Abe, S., S. Rhee, O. Iwanuma, E. Hiroki, N. Yanagisawa, K. Sakiyama, and Y. Ide. 2009. Effect of mechanical stretching on expressions of muscle specific transcription factors MyoD, Myf5, Myogenin and MRF4 in proliferated myoblasts. Anat. Histol. Embryol. 38:305-310.

Baar, K. 2010. Epigenetic control of skeletal muscle fibre type. Acta. Physiol. 199:477487.

Butcher, L. M. and S. Beck. 2008. Future impact of integrated high-throughput methylome analyses on human health and disease. J. Genet. Genomics 35:391-401.

Caliaro, F., L. Maccatrozzo, L. Toniolo, C. Reggiani, F. Mascarello, and M. Patruno. 2005. Myogenic regulatory factors expressed during postnatal hyperplastic growth in porcine muscles. Basic Appl. Myol. 15:55-60.

Collins, C. A., V. F. Gnocchi, R. B. White, L. Boldrin, A. PerezRuiz, F. Relaix, J. E. Morgan, and P. S. Zammit. 2009. Integrated functions of Pax3 and Pax7 in the regulation of proliferation, cell size and myogenic differentiation. PloS one 4:e4475.

Dedieu, S., G. Mazères, P. Cottin, and J. J. Brustis. 2002. Involvement of myogenic regulator factors during fusion in the cell line C. Int. J. Dev. Biol. 46:235-241.

Eckhardt, F., J. Lewin, R. Cortese, V. K. Rakyan, J. Attwood, M. Burger, J. Burton, T. V. Cox, R. Davies, and T. A. Down et al. 2006. DNA methylation profiling of human chromosomes 6 , 20 and 22. Nat. Genet. 38:1378-1385.
Fan, H., M. U. Cinar, C. Phatsara, D. Tesfaye, E. Tholen, C. Looft, and K. Schellander. 2011. Molecular mechanism underlying the differential MYF6 expression in postnatal skeletal muscle of Duroc and Pietrain breeds. Gene 486:8-14.

Fan, X., M. Inda, T. Tunon, and J. S. Castresana. 2002. Improvement of the methylation specific PCR technical conditions for the detection of $\mathrm{p} 16$ promoter hypermethylation in small amounts of tumor DNA. Oncol. Rep. 9:181-183.

Frommer, M., L. E. McDonald, D. S. Millar, C. M. Collis, F. Watt, G. W. Grigg, P. L. Molloy, and C. L. Paul. 1992. A genomic sequencing protocol that yields a positive display of 5methylcytosine residues in individual DNA strands. Proc. Natil. Acad. Sci. USA. 89:1827-1831.

Ghai, S., R. Monga, T. K. Mohanty, M. S. Chauhan, and D. Singh. 2010. Tissue-specific promoter methylation coincides with Cyp19 gene expression in buffalo (Bubalus bubalis) placenta of different stages of gestation. Gen. Comp. Endocrinol. 169:182-189.

Horst, D., S. Ustanina, C. Sergi, G. Mikuz, H. Jurgens, T. Braun, and E. Vorobyov. 2006. Comparative expression analysis of Pax3 and Pax7 during mouse myogenesis. Int. J. Dev. Biol. 50:47-54.

Kim, S. K., H. R. Jang, J. H. Kim, M. Kim, S. M. Noh, K. S. Song, G. H. Kang, H. J. Kim, S. Y. Kim, and H. S. Yoo, and Y. S. Kim. 2008. CpG methylation in exon 1 of transcription factor 4 increases with age in normal gastric mucosa and is associated with gene silencing in intestinal-type gastric cancers. Carcinogenesis 29:1623-1631.

Liu, G. Q., K. Zong, L. L. Zhang, and S. Q. Cao. 2010. Dietary methionine affect meat qulity and myostatin gene exon 1 region methylation in skeletal muscle tissues of broilers. Agric. Sci. China 9:1338-1346.

Nakamura, J., T. Tanaka, Y. Kitajima, H. Noshiro, and K. Miyazaki. 2014. Methylation-mediated gene silencing as biomarkers of gastric cancer: a review. World J. Gastroenterol. 20:11991-12006

Olguin, H. C., Z. Yang, S. J. Tapscott, and B. B. Olwin. 2007. Reciprocal inhibition between $\operatorname{Pax} 7$ and muscle regulatory factors modulates myogenic cell fate determination. J. Cell Biol. 177:769-779.

Palacios, D. and P. L. Puri. 2006. The epigenetic network regulating muscle development and regeneration. J. Cell. Physiol. 207:1-11.

Qiao. M., H. Y. Wu, F. E. Li, S. W. Jiang, Y. Z. Xiong, and C. Y. Deng. 2010. Molecular characterization, expression profile and association analysis with carcass traits of porcine LCAT gene. Mol. Biol. Rep. 37:2227-2234.

Steffens, A. A., G. M. Hong, and L. J. Bain. 2011. Sodium arsenite delays the differentiation of $\mathrm{C} 2 \mathrm{C} 12$ mouse myoblast cells and alters methylation patterns on the transcription factor myogenin. Toxicol. Appl. Pharmacol. 250:154-161.

Takai, D. and P. A. Jones. 2002. Comprehensive analysis of CpG islands in human chromosomes 21 and 22. Proc. Nati. Acad. Sci. USA. 99:3740-3745.

Verner, J., P. Humpolícek, and A. Knoll. 2007. Impact of MYOD family genes on pork traits in Large White and Landrace pigs. J. Anim. Breed. Genet. 124:81-85.

Weintraub, H. 1993. The MyoD family and myogenesis: Redundancy, networks, and thresholds. Cell 75:1241-1244. 
Wu, Q., R. A. Lothe, T. Ahlquist, I. Silins, C. G. Tropé, F. Micci, J. Yeo, S., S. Jeong, J. Kim, J. S. Han, Y. M. Han, and Y. K. Kang. M. Nesland, Z. Suo, and G. E. Lind. 2007. DNA methylation profiling of ovarian carcinomas and their in vitro models identifies $H O X A 9, H O X B 5, S C G B 3 A 1$, and $C R A B P 1$ as novel targets. Mol. Cancer 6:45.

Xiong, Q., J. Chai, P. P. Zhang, J. Wu, S. W. Jiang, R. Zheng, and C. Y. Deng. 2011. MyoD control of SKIP expression during pig skeletal muscle development. Mol. Biol. Rep. 38:267-274. 2007. Characterization of DNA methylation change in stem cell marker genes during differentiation of human embryonic stem cells. Biochem. Biophys. Res. Commun. 359:536-542.

Zelko, I. N., M. R. Mueller, and R. J. Folz. 2010. CpG methylation attenuates Sp1 and Sp3 binding to the human extracellular superoxide dismutase promoter and regulates its cell-specific expression. Free Radic. Biol. Med. 48:895-904. 